\title{
Assisted conception as a potential prognostic factor predicting insulin therapy in pregnancies complicated by gestational diabetes mellitus
}

Azam Kouhkan ${ }^{1,2^{*}}$ (D), Hamid Reza Baradaran ${ }^{3,4}$, Roya Hosseini ${ }^{1,5}$, Arezoo Arabipoor ${ }^{6}$, Ashraf Moini $i^{6,7,8}$, Reihaneh Pirjani ${ }^{7}$, Alireza Khajavi ${ }^{9}$ and Mohammad E. Khamseh ${ }^{3^{*}}$

\begin{abstract}
Background: Advanced maternal age, family history of diabetes, pre-gestational obesity, increased level of HbA1c, history of gestational diabetes mellitus (GDM), and poor pregnancy consequences are considered risk factors for antenatal insulin requirement in women with GDM. However, the role of assisted reproductive technology (ART) in increasing the risk of insulin therapy in pregnancies complicated with GDM remained elusive. The current study aimed to determine the role of ART in predicting insulin therapy in GDM women and investigate the clinical and biochemical factors predicting the need for insulin therapy in pregnancies complicated with GDM.
\end{abstract}

Methods: In this prospective cohort study, 236 Iranian women with GDM were diagnosed by one-step oral glucose tolerance test (OGTT) between October 2014 and June 2017. They were mainly assigned to two groups; the first group ( $n=100$ ) was designated as ART which was further subdivided into two subgroups as follows: 60 participants who received medical nutrition therapy (MNT) and 40 participants who received MNT plus insulin therapy (MNT-IT). The second group ( $n=136$ ) was labeled as the spontaneous conception (SC), consisting of 102 participants receiving MNT and 34 participants receiving MNT in combination with IT (MNT-IT). The demographic, clinical, and biochemical data were compared between groups. Multivariate logistic regression was performed to estimate prognostic factors for insulin therapy.

Results: A higher rate of insulin therapy was observed in the ART group as compared with the SC group (40\% vs. $25 \% ; P<0.001)$. Multivariate logistic regression demonstrated that maternal age $\geq 35$ years [OR: $2.91,95 \% \mathrm{Cl}$ : (1.286.62)], high serum FBS [1.10: (1.04-1.16)], HbA1c [1.91 (1.09-3.34)], and ART treatment [2.94: (1.24-6.96)] were independent risk factors for insulin therapy in GDM women.

Conclusions: Apart from risk factors mentioned earlier, ART may be a possible prognostic factor for insulin therapy in pregnancies complicated with GDM.

Keywords: Gestational diabetes mellitus, Insulin, Prognostic factors, Assisted reproductive technology, Pregnancy

\footnotetext{
* Correspondence: akouhkan@royaninstitute.org; azamkouhkan@yahoo.com;

Khamseh.m@iums.ac.ir; khamseh.m@iums.ac.ir

${ }^{1}$ Reproductive Epidemiology Research Center, Royan Institute for

Reproductive Biomedicine, ACECR, Tehran, Iran

${ }^{3}$ Endocrine Research Center, Institute of Endocrinology and Metabolism, Iran

University of Medical Sciences (IUMS), Firouzeh St., South Vali- Asr Ave., Vali-

Asr Sq, Tehran, Iran

Full list of author information is available at the end of the article
}

(c) The Author(s). 2019 Open Access This article is distributed under the terms of the Creative Commons Attribution 4.0 International License (http://creativecommons.org/licenses/by/4.0/), which permits unrestricted use, distribution, and reproduction in any medium, provided you give appropriate credit to the original author(s) and the source, provide a link to the Creative Commons license, and indicate if changes were made. The Creative Commons Public Domain Dedication waiver (http://creativecommons.org/publicdomain/zero/1.0/) applies to the data made available in this article, unless otherwise stated. 


\section{Introduction}

Assisted reproductive technology (ART) is increasingly being practiced worldwide. Besides, gestational diabetes mellitus (GDM) has become more prevalent in obese women conceived via ART treatments [1]. Several lines of evidence demonstrate that both ART and GDM are associated with adverse pregnancy outcomes as compared to those with natural conception [2, 3]. Current reports indicate that a history of infertility can increase the risk of GDM independent of the known risk factors $[4,5]$. Furthermore, a higher prevalence of GDM in women who became pregnant by ART was previously reported [5]. Therefore, GDM, as a marked comorbidity, should be early diagnosed and managed appropriately.

As the pregnancy proceeds, insulin resistance is gradually increased, especially in the third trimester of the gestational period [6]. Obesity and insulin-resistance reduce the functionality of $\beta$-cells and induce inflammation thought to play key roles in the development of GDM [7]. In this circumstance, early management of GDM which is of immense importance includes medical nutrition therapy (MNT), self-blood glucose monitoring, physical activity, and regular consumption of medications to control hyperglycemia [8]. Approximately 20$60 \%$ of GDM women need pharmacological treatments to control their blood sugar [9]. Insulin is considered a safe and effective medication for women with GDM who failed to respond to medical nutrition therapy [8]. Adequate and accurate control of blood glucose can attenuate adverse maternal and perinatal outcomes [10]. However, factors predicting antenatal insulin requirement in women with GDM have not been fully understood. Some risk factors, such as advanced maternal age, family history of diabetes, pre-gestational obesity, high oral glucose tolerance test (OGTT) values, history of GDM or poor pregnancy consequences, and polycystic ovary syndrome (PCOS) have been previously addressed in the literature $[11,12]$.

However, the role of ART in increasing the risk of insulin therapy in women with GDM remained opaque. Hence, this study was designed to explore the role of ART in predicting insulin therapy in women with GDM. Moreover, we examined the predictive potential of clinical and biochemical parameters for insulin therapy in the management of women with GDM.

\section{Participants and methods}

The present research was a prospective cohort study that included 236 Iranian singleton pregnant women (aged 20-40 years) with GDM who recruited between October 2014 and June 2017. All participants consisted of ART and spontaneous conception (SC) groups enrolled by simple sampling following GDM diagnosis. Medical records of Iranian GDM pregnant women were registered. The ART group included singleton pregnancies conceived following in-vitro fertilization /intra-cytoplasmic sperm injection (IVF/ICSI) or ICSI cycles that referred to the Department of Endocrinology and Female Infertility of the Royan Institute, Tehran, Iran. The protocol of infertility treatment in our institute was in agreement with the standard international guidelines.

The pregnant women with no history of infertility and/or infertility treatments were designated the SC group who referred to the Obstetrics and Gynecology Clinic of Arash Women's Hospital which affiliated with Tehran University of Medical Science. Written informed consent was taken from all participants before the enrollment.

The diagnosis of GDM was made by a one-step OGTT at 24 and 28 weeks of gestation. The American Diabetes Association/International Association of the Diabetes and Pregnancy Study Groups (ADA/IAPDSG) criteria were considered to diagnose GDM [8]. The exclusion criteria were: (1) any systemic disorders, (2) pregravid diabetes or glucose intolerance, (3) previous insulin treatment, (4) consuming oral glucose-lowering drugs (metformin and glibenclamide), (5) vanishing embryos or selective fetal reduction, (6) history of polycystic ovarian syndrome (PCOS), and (7) twin pregnancies. The Institutional Review Board and Ethics committee of the Iran University of Medical Sciences and Royan institute approved the present study.

Clinical and demographic data were obtained from medical records and face-to-face interviews. In these two centers, the weight (without shoes with the least clothes) of women was measured by Seca scale, and the height was determined by a stadiometer. Pre-pregnancy body mass index (BMI) [pre-pregnancy weight $(\mathrm{kg}) /$ height $(\mathrm{m})$ ${ }^{2}$ ] was calculated according to the standard formula. Systolic and diastolic blood pressure was assessed by trained nurses with a mercury sphygmomanometer at 24-28 weeks of gestation. The mean systolic and diastolic blood pressure was recorded in duplicate. Venous blood samples were collected at 24 and 28 weeks of gestation for the determination of fasting blood sugar (FBS), hemoglobin A1c (HbA1c), insulin, a high-sensitivity Creactive protein (hs-CRP), and interleukin-17 (IL-17), as well as the lipid profile, i.e., cholesterol, triglycerides (TG), high density lipoprotein (HDL), low density lipoprotein (LDL), and very-low-density lipoproteins (VLDL), after 8-12 h' fast. The Homeostasis Model Assessment of insulin resistance (HOMA-IR) index was also calculated.

All GDM women referred to an endocrinologist and a dietician for blood sugar management, Medical nutrition therapy (MNT), and nutrition plan, and consultation. Medical nutrition therapy (MNT) was defined as the 
management of GDM with optimal diet (energy content, macronutrient distribution, its quality and amount) to achieve sufficient mother's weight gain and fetal growth, as well as maintaining near-normoglycemia and avoiding the development of ketone bodies and hypoglycemia. The participants were asked to take three main meals with three snacks per day and perform self-monitoring of blood glucose (SMBG). After 2 weeks of MNT, all participants were visited again by an endocrinologist. Fasting and postprandial sugar $(2 \mathrm{~h}$ after breakfast, lunch, and dinner) were evaluated. If FBS was lower than $95 \mathrm{mg} / \mathrm{dl}$, the 1-h postprandial blood sugar level was < $140 \mathrm{mg} / \mathrm{dl}$, and 2-h postprandial blood sugar level was < $120 \mathrm{mg} / \mathrm{dl}, \mathrm{MNT}$ alone continued. Insulin therapy (IT) was initiated by an endocrinologist when medical nutrition therapy failed, and fasting/postprandial blood glucose levels were above the target at any time during pregnancy. Subcutaneous injections of the rapid-acting and/or long-acting insulin were prescribed according to the blood glucose patterns.

The ovarian stimulation protocols and follow-up process after standard IVF/ICSI procedures were described previously in details [13]. ART drugs, the protocol of controlled ovarian stimulation (COS) using standard GnRH agonists or antagonists, as well as the modes of ART (fresh or frozen embryo transfer cycles) were obtained from the medical registry of infertile women. Ovarian hyper-stimulation syndrome (OHSS) is characterized by the increased level of serum estradiol $(>4000 \mathrm{pg} / \mathrm{ml}$ ) along with a large number $(>20$ per ovary) of follicles on the day of human chorionic gonadotropin (hCG) administration. Infertile women who were at higher risk of developing OHSS, frozen embryo transfer was performed by the vitrification method.

Data related to the ART procedures, including menarche age, infertility duration, irregular menstrual cycle, infertility type (secondary vs. primary), history of ovarian hyperstimulation syndrome (OHSS) risk, ovarian stimulation protocol (standard GnRH agonists vs. GnRH antagonists), and the method of ART [fresh embryo transfer (fresh ET) vs. frozen ET)] were obtained from women receiving infertility treatments.

Other variables that were considered in the final analysis were as follows; maternal age, BMI, history of having a first-degree relative with diabetes, prior history of spontaneous abortion, and macrosomic baby, history of GDM, increased OGTT values (GTT-FBS and GTT-2 h), increased levels of HbAlc, mode of conception, and GDM treatment modalities (MNT /MNT- IT).

\section{Statistical analysis}

In the current study, continuous variables were presented as the means and standard error of the mean (mean \pm SEM) and categorical variables were expressed as the percentage. The chi-square test and independent T-tests were applied to compare variables between the two groups as indicated. The univariate logistic regression analysis was carried out to compare the characteristics of participants receiving either MNT-IT or MNT and select the variables for entering in the multivariate model, as well as determining significant predictive factors for insulin requirement in the study population. All statistical analyses were two-sided, and the $p$-value of $<$ 0.05 was considered statistically significant. The analysis of the obtained values was performed by the Stata software version 12 .

Based on previous studies [14-16], a sample size of 236 GDM women would be necessary to obtain a power of $80 \%$ with a significance level $\alpha=5 \%$ to detect a relationship between the type of conception and the need for insulin therapy.

\section{Results}

In this study, 100 GDM women conceived via ART and 136 GDM women conceived via spontaneous conception were included. All participants were stratified based on the treatment modalities receiving during pregnancy [i.e., medical nutrition therapy (MNT) or medical nutrition therapy plus insulin therapy (MNT-IT)]. In the ART group, 60 subjects were in the MNT sub-group and 40 subjects in the MNT-IT subgroup. In the SC group, 102 subjects were assigned to the MNT subgroup and 34 subjects in the MNT-IT subgroup. Figure 1 shows a flow diagram of the categorization of participants. The results showed a higher rate of participants in the ART group who required insulin treatment compared with individuals in the SC group [40 (40\%) vs. 34 (25\%), respectively; $P<0.001$.

The clinical and biochemical characteristics of women in both groups are summarized in Table 1. Based on our results, there was no significant difference between SC and ART groups in terms of the mean maternal age, systolic and diastolic blood pressure, and the number of individuals with a family history of diabetes, prior history of spontaneous abortion, and macrocosmic baby. However, there was a significant difference between the two groups concerning the parity, pre-pregnancy BMI, and history of GDM. Besides, most biochemical characteristics were not significantly different except for serum FBS and hs-CRP levels.

The clinical characteristics between the two groups were stratified based on treatment modalities that are displayed in Table 2. Higher rates of maternal age $\geq 35$ years, multiparty, pre-pregnancy BMI $\geq 25\left(\mathrm{~kg} / \mathrm{m}^{2}\right)$ and prior history of GDM were observed in the MNT-IT subgroup of the SC group; however, such increments were not statistically significant when compared with the MNT subgroup of the ART group. In the ART group, 


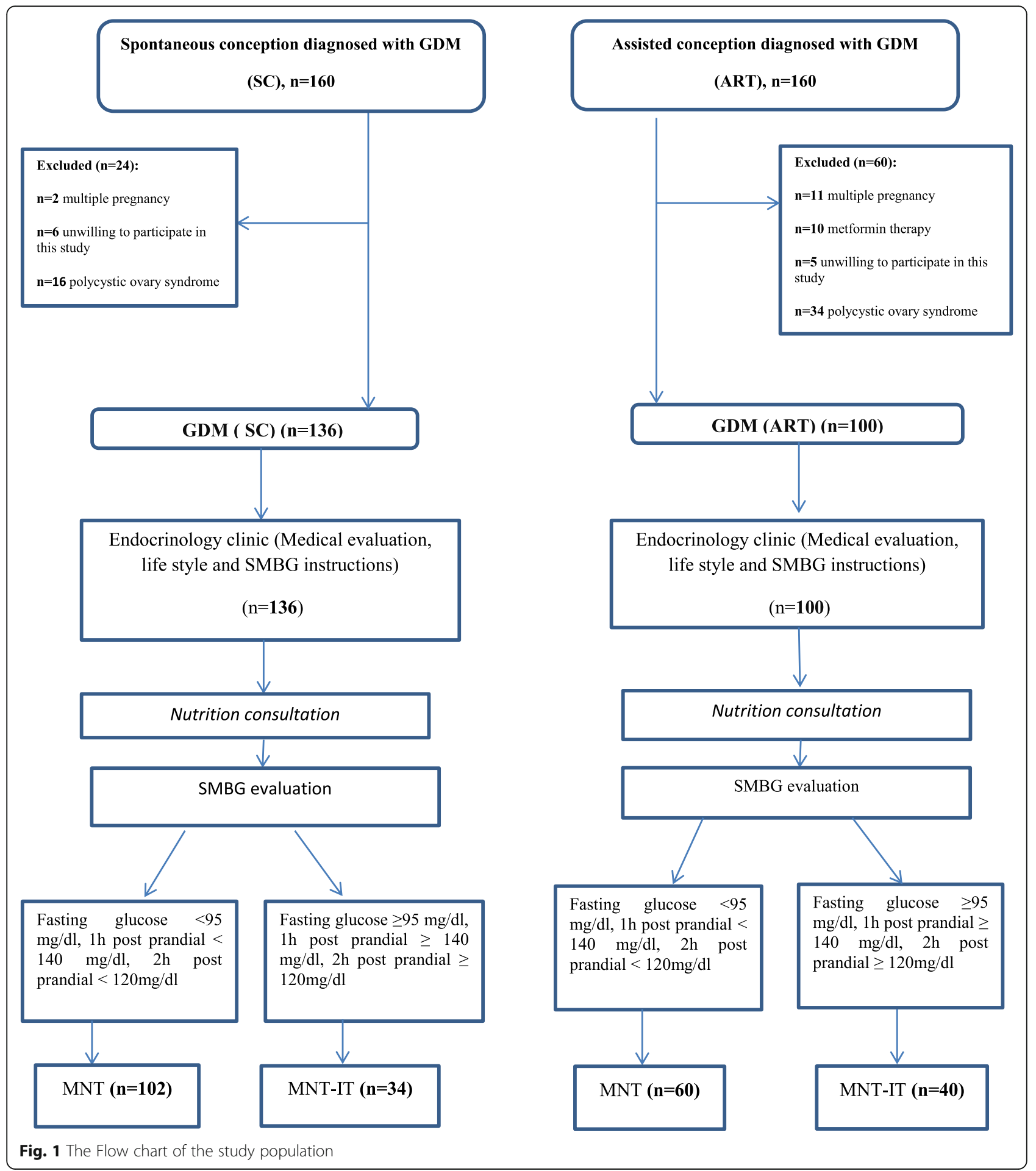

the MNT-IT subgroup had a higher rate of family history of diabetes compared with the MNT subgroup.

The results of the univariate logistic regression analysis are presented in Table 2 and show the risk factors of insulin therapy in the study population. The parameters associated with insulin requirement in total population were as follows; maternal age $\geq 35$ years, family history of diabetes mellitus (DM), pre-pregnancy BMI, previous history of spontaneous abortion, and prior history of GDM. However, there were no significant differences between MNT and MNT-IT subgroups of the ART group in terms of ART parameters $(P>0.05)$ (Table 3$)$. None of the infertility parameters was associated with insulin therapy in this group. 
Table 1 Comparison of clinical and biochemical characteristics between spontaneous conception and ART participants

\begin{tabular}{|c|c|c|c|}
\hline Variables & SC $(n=136)$ & $\operatorname{ART}(n=100)$ & $+P$-value \\
\hline \multicolumn{4}{|l|}{ Clinical } \\
\hline Maternal age (Years, Mean \pm SE) & $31.57 \pm 0.46$ & $32.36 \pm 0.52$ & 0.261 \\
\hline Parity $(n=0), \mathrm{n}(\%)$ & $56(41.2)$ & $88(87.1)$ & $0.001^{*}$ \\
\hline Family history of DM, (Yes, n \%) & $52(38.2)$ & $42(41.6)$ & 0.602 \\
\hline Systolic blood pressure (Mean \pm SE) & $107.07 \pm 0.87$ & $106.68 \pm 0.99$ & 0.769 \\
\hline Diastolic blood pressure (Mean \pm SE) & $68.59 \pm 0.72$ & $66.83 \pm 0.76$ & 0.098 \\
\hline Pre-pregnancy BMI (Mean \pm SE) & $25.89 \pm 0.42$ & $27.32 \pm 0.40$ & $0.018^{*}$ \\
\hline Prior history of spontaneous abortion, (Yes), n (\%) & $36(29.1)$ & $32(31.7)$ & 0.670 \\
\hline Prior history of GDM, (Yes), n (\%) & $18(13.2)$ & $1(0.9)$ & $0.001^{*}$ \\
\hline Prior history of macrosomia, (Yes), n (\%) & $6(4.4)$ & $1(0.9)$ & 0.124 \\
\hline \multicolumn{4}{|l|}{ Biochemical } \\
\hline GTT-FBS (mg/dl)(Mean \pm SE) & $93.38 \pm 0.87$ & $93.13 \pm 0.96$ & 0.851 \\
\hline GTT-1 h(mg/dl)(Mean \pm SE) & $162.93 \pm 4.11$ & $158.22 \pm 4.72$ & 0.455 \\
\hline GTT-2 h(mg/dl)(Mean \pm SE) & $134.29 \pm 3.71$ & $133.26 \pm 3.67$ & 0.847 \\
\hline FBS (mg/dl)(Mean \pm SE) & $84.21 \pm 1.05$ & $88.23 \pm 0.95$ & $0.006^{*}$ \\
\hline HbA1c (\%) (Mean \pm SE) & $4.98 \pm 0.10$ & $5.07 \pm 0.63$ & 0.297 \\
\hline TG (mg/dl)(Mean \pm SE) & $200.61 \pm 6.13$ & $193.42 \pm 5.62$ & 0.254 \\
\hline Cholesterol (mg/dl)(Mean \pm SE) & $219.91 \pm 3.52$ & $210.86 \pm 4.43$ & 0.107 \\
\hline $\mathrm{HDL}(\mathrm{mg} / \mathrm{dl})($ Mean $\pm \mathrm{SE})$ & $64.17 \pm 1.34$ & $63.49 \pm 1.26$ & 0.715 \\
\hline $\mathrm{LDL}(\mathrm{mg} / \mathrm{dl})($ Mean $\pm \mathrm{SE})$ & $116.13 \pm 3.01$ & $110.31 \pm 4.01$ & 0.238 \\
\hline VLDL (mg/dl)(Mean \pm SE) & $40.05 \pm 1.24$ & $37.19 \pm 1.28$ & 0.115 \\
\hline Hs-CRP (Mean \pm SE) & $4.69 \pm 0.40$ & $7.21 \pm 0.83$ & $0.005^{*}$ \\
\hline IL-17 (Mean \pm SE) & $1.19 \pm 0.26$ & $2.66 \pm 0.95$ & 0.161 \\
\hline Insulin (Mean \pm SD) & $13.57 \pm 140$ & $13.98 \pm 0.96$ & 0.821 \\
\hline HOMA-IR & $2.90 \pm 0.34$ & $3.09 \pm 0.23$ & 0.672 \\
\hline
\end{tabular}

SC spontaneous conception, ART Assisted reproductive technology, IL-17 Interleukin- 17, Hs-CRP High-sensitivity C - reactive protein, The Homeostasis Model Assessment of insulin resistance $(H O M A-I R)$ index = [Glucose] * [Insulin] / 405 (Glucose in $\mathrm{mg} / \mathrm{dl}$ )

${ }^{*} P<0.05$ was considered statistically significant

† T-test compared the mean difference between the SC group and ART group

The biochemical values of the SC and ART participants were stratified according to the treatment modalities that are depicted in Table 4. The mean concentrations of FBS and HbA1c were significantly higher in the MNT-IT subgroup of the SC group compared with the MNT subgroup. Similar findings were observed in the MNT-IT subgroup of the ART group when compared with MNT subgroup. The higher levels of one- and two-hour glucose after OGTT were observed in the MNT-IT subgroup of the SC group in comparison with the MNT subgroup. However, such values were not significantly different between the MNT and MNT-IT subgroups of the ART population $(\mathrm{P}>0.05)$. The mean concentrations of TG and VLDL were significantly higher in the MNT-IT subgroup of the ART group as compared with the MNT subgroup. The mean levels of the inflammatory markers were higher in the MNT-IT subgroup compared with the MNT subgroup of the ART group. In the total population, higher levels of GTT-FBS, GTT-1 h, GTT-2 h, FBS, and HbA1c, as well as hs-CRP, were observed in the MNT-IT subgroup compared with the MNT subgroup of the ART group.

The analysis of multivariate logistic regression was conducted to determine the predictive factors linked with insulin therapy (Table 5). Factors identified as prognostic factors of insulin therapy were the age equal to or above 35 years old [OR: 2.91, 95\% CI: (1.28-6.62)], increased levels of GTT- FBS [1.10: (1.04-1.16)], HbA1c [1.91 (1.09-3.34)], as well as ART treatment. The mode of conception (ART treatment) was identified as the independent prognostic factor for insulin requirement in GDM women after the adjustment (or controlling) of other confounding factors or covariates [OR: 2.94, 95\% CI: (1.24-6.96)].

\section{Discussion}

The present study found that maternal age $\geq 35$ years old, elevated fasting glucose, and increased levels of HbA1c were the independent risk factor for insulin 
Table 2 Comparison of clinical parameters between parturients with spontaneous and ART conception stratified based on treatment modalities

\begin{tabular}{|c|c|c|c|c|c|c|c|c|c|c|}
\hline \multirow[t]{2}{*}{ Variables } & \multicolumn{4}{|c|}{ SC $(n=136)$} & \multicolumn{4}{|c|}{$\operatorname{ART}(n=100)$} & \multirow{2}{*}{$\underset{c}{\mathrm{OR} 3}(\mathrm{Cl} 5 \%)$} & \multirow{2}{*}{$\begin{array}{l}P \text { - } \\
\text { value }\end{array}$} \\
\hline & $\begin{array}{l}\text { MNT }(n= \\
102)\end{array}$ & $\begin{array}{l}\text { MNI-IT }(n= \\
34)\end{array}$ & $\underset{\mathrm{a}}{\mathrm{O}} \mathrm{OR} 1(\mathrm{Cl} 95 \%)$ & $\begin{array}{l}P \text { - } \\
\text { value }\end{array}$ & $\begin{array}{l}\text { MNT }(n= \\
60)\end{array}$ & $\begin{array}{l}\text { MNT-IT } \\
(n=40)\end{array}$ & $\begin{array}{l}\text { OR2 (Cl } \\
95 \%)^{b}\end{array}$ & $\begin{array}{l}P- \\
\text { value }\end{array}$ & & \\
\hline $\begin{array}{l}\text { Maternal age (Years, Mean } \pm \\
\text { SE) }\end{array}$ & $\begin{array}{l}30.64 \pm \\
0.53\end{array}$ & $\begin{array}{l}34.38 \pm \\
0.73\end{array}$ & $\begin{array}{l}1.17(1.07- \\
1.28)\end{array}$ & $0.001^{*}$ & $\begin{array}{l}32.05 \pm \\
0.77\end{array}$ & $32.65 \pm 0.62$ & $\begin{array}{l}1.02(0.95- \\
1.10)\end{array}$ & 0.576 & $\begin{array}{l}1.94(1.10- \\
3.41)\end{array}$ & $0.023^{*}$ \\
\hline Maternal age $\geq 35$ years,n (\%) & $26(25.5)$ & $16(47.0)$ & $\begin{array}{l}2.6(1.16- \\
5.82)\end{array}$ & $0.018^{*}$ & $19(31.7)$ & $15(37.5)$ & $\begin{array}{l}1.29(0.55- \\
2.99)\end{array}$ & 0.546 & $\begin{array}{l}1.87(1.05- \\
3.33)\end{array}$ & $0.032^{*}$ \\
\hline Parity $(n=0), n(\%)$ & $46(45.1)$ & $10(29.4)$ & $\begin{array}{l}11.97(0.86- \\
4.54)\end{array}$ & 0.108 & $50(83.3)$ & $37(92.5)$ & $\begin{array}{l}0.41(0.10- \\
1.58)\end{array}$ & 0.182 & $\begin{array}{l}0.84(0.47- \\
1.47)\end{array}$ & 0.535 \\
\hline $\begin{array}{l}\text { Family history of DM (Yes, } \mathrm{n} \\
\% \text { \%) }\end{array}$ & $35(34.3)$ & $17(50.0)$ & $\begin{array}{l}1.91(0.87- \\
4.20)\end{array}$ & 0.103 & $20(33.3)$ & $22(55.0)$ & $\begin{array}{l}2.44(1.07- \\
5.56)\end{array}$ & $0.033^{*}$ & $\begin{array}{l}2.17(1.24- \\
3.79)\end{array}$ & $0.007^{*}$ \\
\hline $\begin{array}{l}\text { Systolic blood pressure } \\
\text { (Mean } \pm \text { SE) }\end{array}$ & $\begin{array}{l}106.37 \pm \\
1.01\end{array}$ & $\begin{array}{l}109.11 \pm \\
0.72\end{array}$ & $\begin{array}{l}1.03(0.99- \\
1.07)\end{array}$ & 0.176 & $\begin{array}{l}107.25 \pm \\
1.17\end{array}$ & $106.0 \pm 1.82$ & $\begin{array}{l}0.99(0.95- \\
1.03)\end{array}$ & 0.542 & $\begin{array}{l}1.01(0.98- \\
1.03)\end{array}$ & 0.424 \\
\hline $\begin{array}{l}\text { Diastolic blood pressure } \\
\text { (Mean } \pm \text { SE) }\end{array}$ & $\begin{array}{l}68.22 \pm \\
0.83\end{array}$ & $\begin{array}{l}69.71 \pm \\
1.42\end{array}$ & $\begin{array}{l}1.02(0.97- \\
1.07)\end{array}$ & 0.367 & $\begin{array}{l}66.83 \pm \\
0.98\end{array}$ & $67.0 \pm 1.25$ & $\begin{array}{l}1.00(0.96- \\
1.06)\end{array}$ & 0.915 & $\begin{array}{l}1.0(0.97- \\
1.04)\end{array}$ & 0.574 \\
\hline $\begin{array}{l}\text { Pre-pregnancy BMI (Mean } \pm \\
\text { SE) }\end{array}$ & $\begin{array}{l}25.44 \pm \\
0.49\end{array}$ & $\begin{array}{l}27.31 \pm \\
0.81\end{array}$ & $\begin{array}{l}1.08(1.00- \\
1.17)\end{array}$ & 0.059 & $\begin{array}{l}27.22 \pm \\
0.46\end{array}$ & $27.52 \pm 0.76$ & $\begin{array}{l}1.01(0.95- \\
1.12)\end{array}$ & 0.726 & $\begin{array}{l}1.94(1.09- \\
3.45)\end{array}$ & $0.022^{*}$ \\
\hline $\begin{array}{l}\text { Pre-pregnancy BMI } \geq 25(\mathrm{~kg} / \\
\left.\mathrm{m}^{2}\right), \mathrm{n}(\%)\end{array}$ & $49(49.1)$ & $23(71.9)$ & $\begin{array}{l}2.65(1.12- \\
6.31)\end{array}$ & $0.024^{*}$ & $43(71.7)$ & $29(72.5)$ & $\begin{array}{l}1.04(0.43- \\
2.55)\end{array}$ & 0.928 & $\begin{array}{l}1.92(1.05- \\
3.51)\end{array}$ & 0.034 \\
\hline $\begin{array}{l}\text { History of spontaneous } \\
\text { abortion, } \mathrm{n}(\%)\end{array}$ & $26(26.0)$ & $13(38.2)$ & $\begin{array}{l}1.76(0.77- \\
4.02)\end{array}$ & 0.175 & $16(26.7)$ & $16(40)$ & $\begin{array}{l}1.83(0.78- \\
4.30)\end{array}$ & 0.161 & $\begin{array}{l}1.90(1.12- \\
3.23)\end{array}$ & $0.018^{*}$ \\
\hline History of GDM, (Yes, n \%) & $8(7.8)$ & $10(29.4)$ & $\begin{array}{l}4.90(1.74- \\
13.74)\end{array}$ & $0.001^{*}$ & $1(1.7)$ & $0(0)$ & - & 1 & $\begin{array}{l}2.66(1.03- \\
6.84)\end{array}$ & $0.043^{*}$ \\
\hline $\begin{array}{l}\text { History of macrosomia, (Yes, n } \\
\%)\end{array}$ & $4(3.9)$ & $2(5.8)$ & $\begin{array}{l}1.53(0.27- \\
8.76)\end{array}$ & 0.630 & $1(1.7)$ & $0(0)$ & $\begin{array}{l}0.87(0.16- \\
4.60)\end{array}$ & 0.872 & $\begin{array}{l}0.66(0.13- \\
3.35)\end{array}$ & 0.619 \\
\hline
\end{tabular}

CI Confidence Interval, GDM gestational diabetes mellitus, SC Spontaneous Conception, ART Assisted Reproductive Technology, MNT Medical Nutrition Therapy, MNT-IT Medical Nutrition Therapy plus Insulin Therapy

${ }^{*} P<0.05$ was considered statistically significant

${ }^{a}$ OR1; Fitting GDM treatment modality as the outcome of the univariate regression models. The reference group was the MNT subgroup compared to the MNT-IT in SC group

b OR2; Fitting GDM treatment modality as the outcome of the univariate regression models; The reference group was the MNT subgroup compared to the MNT-IT in ART group

' OR3; Fitting GDM treatment modality as the outcome of the univariate regression models; The reference group was the MNT subgroup compared to the MNT-IT in the total population

Table 3 Infertility parameters of ART-conceived parturients stratified based on the treatment modalities

\begin{tabular}{llll}
\hline Variables & $\begin{array}{l}\text { MNT } \\
(n=60)\end{array}$ & MNT-IT $(n=40)$ & $P$-value \\
\hline Menarche age, years (Mean \pm SE) & $13.1 \pm 0.2$ & $13.6 \pm 0.3$ & 0.532 \\
Infertility duration, years, (Mean \pm SE) & $6.2 \pm 0.5$ & $7.5 \pm 0.8$ & 0.117 \\
Irregular menstrual cycle, $\mathrm{n}(\%)$ & $7(11.7)$ & $3(7.5)$ & 0.496 \\
Infertility type (Secondary), $\mathrm{n}(\%)$ & $25(41.7)$ & $17(42.5)$ & $17(42.5)$ \\
Prior OHSS risk, n (\%) & $23(38.3)$ & & 0.934 \\
COH protocol & & $35(87.5)$ & 0.677 \\
$\quad$ Standard long GnRH agonist, n (\%) & $44(77.2)$ & & 0.199 \\
ART mode & & $23(57.5)$ & 0.587 \\
$\quad$ Fresh ET, $\mathrm{n}(\%)$ & $28(51.9)$ &
\end{tabular}

MNT Medical Nutrition Therapy, MNT-IT Medical Nutrition Therapy plus Insulin Therapy, Fresh ET Fresh embryo transfer ${ }^{*} P<0.05$ was considered statistically significant 
Table 4 Comparison of biochemical parameters between parturients with spontaneous and ART conception stratified based on treatment modalities

\begin{tabular}{|c|c|c|c|c|c|c|c|}
\hline \multirow[t]{2}{*}{ Variables } & \multicolumn{3}{|l|}{ SC $(n=136)$} & \multicolumn{3}{|l|}{$\operatorname{ART}(n=100)$} & \multirow{2}{*}{$\begin{array}{l}P- \\
\text { value }\end{array}$} \\
\hline & $\operatorname{MNT}(n=102)$ & MNI-IT $(n=34)$ & $P$-value ${ }^{a}$ & $\mathrm{MNT}(n=60)$ & MNT-IT $(n=40)$ & $P$-value ${ }^{b}$ & \\
\hline GTT-FBS (mg/dl)(Mean \pm SE) & $91.69 \pm 0.95$ & $98.18 \pm 1.66$ & $0.001^{*}$ & $90.67 \pm 1.20$ & $96.92 \pm 1.42$ & $0.001^{*}$ & $0.002^{*}$ \\
\hline GTT-1 h (mg/dl)(Mean \pm SE) & $156.10 \pm 4.46$ & $183.90 \pm 8.66$ & $0.003^{*}$ & $159.14 \pm 5.98$ & $156.82 \pm 7.98$ & 0.813 & $0.014^{*}$ \\
\hline GTT-2 h (mg/dl)(Mean \pm SE) & $129.38 \pm 4.19$ & $147.40 \pm 7.34$ & $0.003^{*}$ & $131.0 \pm 4.50$ & $136.58 \pm 6.39$ & 0.464 & $0.046^{*}$ \\
\hline FBS (mg/dl) (Mean \pm SE) & $82.89 \pm 1.21$ & $88.03 \pm 1.77$ & $0.032^{*}$ & $85.98 \pm 0.99$ & $91.44 \pm 1.77$ & $0.004^{*}$ & $0.030^{*}$ \\
\hline HbA1c (\%) (Mean \pm SE) & $4.92 \pm 0.07$ & $5.40 \pm 0.12$ & $0.005^{*}$ & $4.85 \pm 0.10$ & $5.16 \pm 0.08$ & $0.022^{*}$ & $0.004^{*}$ \\
\hline TG (mg/dl) (Mean \pm SE) & $201.12 \pm 6.83$ & $199.11 \pm 13.71$ & 0.887 & $175.31 \pm 8.16$ & $204.97 \pm 9.69$ & $0.026^{*}$ & 0.065 \\
\hline Cholesterol (mg/dl) (Mean \pm SE) & $221.33 \pm 4.20$ & $215.71 \pm 6.36$ & 0.491 & $202.09 \pm 4.58$ & $223.13 \pm 7.97$ & $0.019^{*}$ & 0.066 \\
\hline $\mathrm{HDL}(\mathrm{mg} / \mathrm{dl})($ Mean $\pm \mathrm{SE})$ & $64.61 \pm 1.56$ & $62.85 \pm 2.60$ & 0.573 & $65.20 \pm 1.74$ & $60.81 \pm 1.65$ & 0.097 & 0.083 \\
\hline LDL $(\mathrm{mg} / \mathrm{dl})($ Mean $\pm \mathrm{SE})$ & $117.30 \pm 3.89$ & $112.52 \pm 6.54$ & 0.496 & $101.83 \pm 4.35$ & $121.42 \pm 6.93$ & $0.014^{*}$ & 0.105 \\
\hline VLDL (mg/dl) (Mean \pm SE) & $40.19 \pm 1.36$ & $39.59 \pm 2.84$ & 0.836 & $35.06 \pm 1.66$ & $40.90 \pm 1.92$ & $0.029^{*}$ & 0.089 \\
\hline hs-CRP (mg/l) (Mean \pm SE) & $4.60 \pm 0.41$ & $5.06 \pm 1.16$ & 0.651 & $6.45 \pm 0.75$ & $8.69 \pm 1.95$ & $0.049^{*}$ & $0.010^{*}$ \\
\hline IL-17(pg/mL) (Mean \pm SE) & $1.21 \pm 0.27$ & $0.70 \pm 0.60$ & 0.660 & $0.91 \pm 0.19$ & $5.52 \pm 2.35$ & $0.017^{b}$ & 0.061 \\
\hline Insulin (mU/L) (Mean \pm SE) & $12.90 \pm 1.64$ & $15.87 \pm 2.58$ & 0.375 & $13.26 \pm 1.36$ & $14.92 \pm 1.29$ & 0.411 & 0.191 \\
\hline HOMA-IR & $2.76 \pm 0.42$ & $3.39 \pm 0.49$ & 0.443 & $2.86 \pm 0.33$ & $3.40 \pm 0.31$ & 0.255 & 0.202 \\
\hline
\end{tabular}

GDM Gestational Diabetes Mellitus, SC Spontaneous Conception, ART Assisted Reproductive Technology, MNT Medical Nutrition Therapy, MNT-IT Medical Nutrition Therapy plus Insulin Therapy

The Homeostasis Model Assessment of insulin resistance (HOMA-IR) index = [Glucose] * [Insulin] / 405 (Glucose in mg/dl)

${ }^{*} P<0.05$ was considered significant

a T-test compared the mean difference between MNT and MNT-IT subgroups in the SC group

${ }^{\mathrm{b}}$ T-test compared the mean difference between MNT and MNT-IT subgroups in the ART group

${ }^{c}$ T-test compared the mean difference between MNT and MNT-IT subgroups in total population

therapy. Furthermore, infertility treatment using assisted reproductive technology may be a possible predictive factor for insulin therapy in women with GDM.

The prevalence of GDM in Iran ranges from 1.3 to $18.8 \%$ in different geographical regions [16]. A recent systematic review and meta-analysis revealed that GDM treatment reduces the risk of delivering infants with macrosomia (i.e., being large-for-gestational-age birth), shoulder dystocia, and gestational hypertension. Of note, GDM treatment causes no significant increase in the risk

Table $\mathbf{5}$ The multivariate logistic regression analysis for the risk factors associated with insulin therapy

\begin{tabular}{ll}
\hline Model & OR $(\mathrm{Cl} 95 \%)^{\mathrm{a}}$ \\
\hline Age $\geq 35 \mathrm{yr}$ (Yes/No) & $2.91(1.28-6.62) \dagger$ \\
Prior history of GDM (Yes/No) & $3.22(0.83-12.51)$ \\
GTT-FBS (mg/dl) & $1.10(1.04-1.16) \dagger$ \\
GTT-2 h (mg/dl) & $1.01(0.99-1.02)$ \\
Family history of DM (Yes/No) & $1.06(0.45-2.45)$ \\
$\mathrm{HbA}_{1} \mathrm{C}(\%)$ & $1.91(1.09-3.34) \dagger$ \\
$\mathrm{BMI}^{2} 25\left(\mathrm{~kg} / \mathrm{m}^{2}\right)$ & $2.12(0.84-5.37)$ \\
Mode of conception (ART/SC) & $2.94(1.24-6.96) \dagger$ \\
\hline
\end{tabular}

Data are presented as odds ratios (95\% confidence interval) MNT-IT was compared to MNT: Reference group was MNT $\dagger P<0.05$ was considered statistically significant

${ }^{\text {a }}$ OR; Fitting GDM treatment modality as the outcome of the multivariate regression models; of small-for-gestational-age birth [17]. Regarding the global increment in gestational diabetes, determination of high-risk populations requiring insulin therapy is crucial. Lifestyle modification is the first-line therapy for the management of women with GDM. However, some GDM women require insulin therapy as they the change in their lifestyle would not be sufficient alone.

Assisted conception, a standard treatment for infertility, is growing worldwide. Several unknown and concomitant factors in women conceived via ART make them prone to develop complications during their pregnancy, such as gestational diabetes which influences the clinical practice. Recently, Chen et al. [18] observed that peripheral insulin sensitivity is reduced in IVF-conceived women. They also reported the alternation of glucose metabolism (impaired glucose tolerance) in IVF-conceived mice. On the basis of the current data, insulin requirement was significantly higher in the ART group compared with the SC group (40\% vs. $25 \%)$. Previously, antenatal insulin requirement was reported in $10.8-52.8 \%$ of GDM women after spontaneous conception $[5,19]$.

Several studies investigated clinical and biochemical parameters predicting the need for insulin therapy in GDM women who spontaneously conceived $[11,12,19-$ 22]. Moreover, some studies suggested similar prognostic factors, including advanced age [11, 23], elevated fasting glucose $[14,15,20,23]$, elevated two-hour glucose 
[14], prior history of GDM [15], and HbA1c [12, 15, 20, 21] for insulin treatment. Conversely, some reports demonstrated that the elevated pre-pregnancy BMI [12, 14, $15,23]$, family history of diabetes $[12,20]$, and elevated 1-h blood glucose after GTT [14, 15, 20] were potentially independent prognostic factors. More recently, Barens et al. indicated a prediction model for insulin therapy in GDM women. According to this model, seven significant independent prognostic factors have been introduced, namely maternal age $>30$ years, pre-gravid obesity (BMI $\geq 30 \mathrm{~kg} / \mathrm{m}^{2}$ ), prior history of GDM, FBS $\geq$ $5.3 \mathrm{mmol} / \mathrm{l}, \quad \mathrm{HbA} 1 \mathrm{c} \geq 5.5 \%$ at the initial diagnosis of GDM, early diagnosis of GDM ( $<24$ weeks of gestation), and family history of diabetes. They concluded that 85.7-93.1\% of women had six to seven prognostic factors mentioned above, but $9.3-14 \%$ of women had no or one prognostic factor [11].

The present results revealed that age $\geq 35$ years, elevated GTT-FBS, and HbA1c were the independent risk factors for insulin therapy. Interestingly, the current study found a new prognostic factor for insulin therapy in pregnant women with GDM. The risk of insulin requirement was 2.94 folds higher in the ART group compared with the SC group. However, little is known about the association between ART and the risk of GDM. Previous evidence showed that infertile women and ART population were susceptible to develop GDM [4, 13]; yet, the mechanism underlying ART-induced insulin resistance and insulin requirement is partially understood. We assessed the impact of some aspects of ART properties on antenatal insulin requirement and observed no significant difference between MNT and MNT-IT subgroups of the ART group with respect to the ART parameters. Several hypotheses may be proposed in this regard.

First, the experimental study showed ART-induced endothelial dysfunction and arterial hypertension, glucose intolerance, and insulin resistance [24]. Second, some ART characteristics may be in charge of insulin resistance and the need for insulin therapy, such as PCOS [25], the number of embryo transfer, and administration of $\mathrm{GnRH}$ agonist during the COS cycle in ART. Third, infertile women usually receive exogenous progesterone during the luteal phase and at the first trimester of pregnancy, which may be associated with gestational diabetes and insulin resistance. Similar mechanisms might be proposed for insulin requirement in patients who undergo ART treatment. Nunes et al. found that progesterone- particularly at pharmacological doses- increased the generation of reactive oxygen species (ROS), and it could be toxic to pancreatic $\beta$-cells as a result of oxidative stress [26].

Moreover, Wada et al. [27] showed the molecular mechanisms of progesterone involved in the pathogenesis of insulin resistance during pregnancy. They indicated that progesterone could induce insulin resistance by the inhibition of GLUT-4 translocation, a decrease in the expression of the insulin receptor substrate-1 (IRS-1), and the uptake of glucose by adipocytes. The degradation of IRS-1 is one of the primary mechanisms that could cause insulin resistance when exposed to pro-inflammatory cytokines [27]. Notably, our data showed the increased serum concentrations of inflammatory markers in the ART group. Furthermore, higher levels of inflammatory biomarkers were observed in the MNT-IT than those in the MNT group. Previous research also demonstrated the increased levels of hs-CRP in GDM women who underwent IVF-ET cycles [28].

Furthermore, recent evidence showed a correlation of the elevated hs-CRP [29] and pro-inflammatory cytokines $[6,7]$ with the development of GDM and insulin resistance. More recently, IL-13, as an inflammatory marker, was found to be associated with the conversion of normoglycemia into type 2 diabetes mellitus and the initiation of insulin therapy [30]. Hence, inflammatory biomarkers may have indirectly affected insulin requirement.

The current study demonstrates that assisted conception could be a prognostic factor for insulin requirement in GDM populations. However, there were some limitations in our study. We could not evaluate all aspects of ART characteristics, and only a limited number of inflammatory biomarkers were evaluated. Another limitation was the lower number of women requiring insulin treatment. Moreover, the current research was performed in Iranian GDM women. This may limit the generalizability of the findings to other racial and ethnic groups. It is necessary to study large populations with other racial/ethnic groups in the future. Additionally, it is possible that the underlying infertility, as opposed to ART, could account for the study findings and the present study was not capable of categorizing the effects of assisted conception (ART) and nature of infertility; hence, it is critical to consider this issue in future studies on infertile patients who undergo non-IVF treatment as a separate cohort.

In conclusion, our findings confirm that age $\geq 35$ years old, elevated levels of GTT-FBS and HbA1c are regarded as the independent risk factors for insulin therapy in GDM population. Furthermore, assisted conception could be a predictive factor for insulin therapy in pregnancies complicated with GDM. However, this study is the first report in this field, and more studies are warranted to corroborate these results.

\section{Abbreviations}

ADA/IAPDSG: American diabetes association/ International association of diabetes and pregnancy study groups; ANOVA: Analysis of variance; aOR: Adjusted odds ratio; ART: Assisted reproductive technology; BSP: Blood sugar profile; COS: Controlled ovarian stimulation; GDM: Gestational diabetes 
mellitus; HbA1c: Hemoglobin A1c; HDL: High density lipoprotein; HOMAIR: Homeostasis model assessment of insulin resistance; hs-CRP: Highsensitivity C-reactive protein; IL-17: Interleukin-17; IRS-1: Insulin receptor substrate-1; IT: Insulin therapy; IVF/ICSI: In-vitro fertilization/ Intra-cytoplasmic sperm injection; LDL: Low density lipoprotein; MNT: Medical nutrition therapy; OGTT: Oral glucose tolerance test; OHSS: Ovarian hyperstimulation syndrome; PCOS: Polycystic ovary syndrome; ROS: Reactive oxygen species; SC: Spontaneous conception; SMBG: Self-monitoring of blood glucose; TG: Triglycerides; VLDL: Very-low-density lipoproteins

\section{Acknowledgments}

The authors would like to thank Royan institute and hospitals related to the Ministry of Health and Medical Education, as well as patients for their invaluable contributions to the performance of the current research.

\section{Authors' contributions}

$A$ K , MEK, RP, RH, and HRB: contributed to the research design. AK, AM, RP, $\mathrm{RH}, \mathrm{HRB}$, and $\mathrm{AA}$ contributed to the selection of patients, data collection, interpretation of the data, and drafting the manuscript. AK wrote the manuscript. AKH assisted in the analysis of the data. All authors read and approved the final version of the manuscript.

\section{Funding}

No financial support

\section{Availability of data and materials}

The datasets used and/or analyzed during the current study are available upon the request from the corresponding authors.

\section{Ethics approval and consent to participate}

The Institutional Review Boards and the Ethics Committee of the Iran University of Medical Sciences and Royan Institute, Tehran, Iran approved the present study (Date: 2015-09-4, Ethical Code: IR.IUMS.REC.1396.25469 and Date: 2014-09-4, Ethical Code: IR.ACECR.ROYAN.REC.1393.2). All procedures performed in this research, including recruiting participants were in accordance with the ethical guidelines of the Iran University of Medical Science, Royan institute, National Research Committee, and Helsinki Declaration (1964) and its later amendments or comparable ethical standards.

\section{Consent for publication}

Not applicable.

\section{Competing interests}

The authors declare that they have no competing interests.

\begin{abstract}
Author details
${ }^{1}$ Reproductive Epidemiology Research Center, Royan Institute for Reproductive Biomedicine, ACECR, Tehran, Iran. ${ }^{2}$ Department of Interdisciplinary Research in Diabetes, Obesity and Metabolism, Cell Science Research Center, Royan Institute for Stem Cell Biology and Technology, ACECR, Tehran 19395-4644, Iran. ${ }^{3}$ Endocrine Research Center, Institute of Endocrinology and Metabolism, Iran University of Medical Sciences (IUMS), Firouzeh St., South Vali- Asr Ave., Vali- Asr Sq, Tehran, Iran. ${ }^{4}$ Ageing Clinical \& Experimental Research Team, Institute of Applied Health Sciences, University of Aberdeen, Aberdeen AB25 2ZD, Scotland, UK. ${ }^{5}$ Department of Andrology, Reproductive Biomedicine Research Center, Royan Institute for Reproductive Biomedicine, ACECR, Tehran, Iran. ${ }^{6}$ Department of Endocrinology and Female Infertility, Reproductive Biomedicine Research Center, Royan Institute for Reproductive Biomedicine, ACECR, Tehran, Iran. ${ }^{7}$ Department of Gynecology and Obstetrics, Arash Women's Hospital, Tehran University of Medical Sciences, Tehran, Iran. ${ }^{8}$ Breast Disease Research Center (BDRC), Tehran University of Medical Sciences, Tehran, Iran. ${ }^{9}$ Student Research Committee, Faculty of Paramedical Sciences, Shahid Beheshti University of Medical Sciences, Tehran, Iran.
\end{abstract}

Received: 19 June 2019 Accepted: 23 September 2019 Published online: 27 October 2019

\section{References}

1. Tobias DK, Chavarro JE, Williams MA, Buck Louis GM, Hu FB, Rich-Edwards J, et al. History of infertility and risk of gestational diabetes mellitus: a prospective analysis of 40,773 pregnancies. Am J Epidemiol. 2013;178(8): 1219-25.

2. Pinborg A, Wennerholm U-B, Romundstad L, Loft A, Aittomaki K, Söderström-Anttila $V$, et al. Why do singletons conceived after assisted reproduction technology have adverse perinatal outcome? Systematic review and meta-analysis. Hum Reprod Update. 2012:19(2):87-104.

3. Catalano PM, Mclntyre HD, Cruickshank JK, McCance DR, Dyer AR, Metzger $\mathrm{BE}$, et al. The hyperglycemia and adverse pregnancy outcome study: associations of GDM and obesity with pregnancy outcomes. Diabetes Care. 2012;35(4):780-86

4. Holst S, Kjær SK, Jørgensen ME, Damm P, Jensen A. Fertility problems and risk of gestational diabetes mellitus: a nationwide cohort study. Fertil Steril. 2016;106(2):427-34 e1

5. Wang $Y$, Nikravan $R$, Smith $H$, Sullivan E. Higher prevalence of gestational diabetes mellitus following assisted reproduction technology treatment. Hum Reprod. 2013;28(9):2554-61.

6. Saisho Y, Miyakoshi K, Tanaka M, Shimada A, Ikenoue S, Kadohira I, et al. Beta cell dysfunction and its clinical significance in gestational diabetes. Endocr J. 2010:57(11):973-80.

7. Abell SK, De Courten B, Boyle JA, Teede HJ. Inflammatory and other biomarkers: role in pathophysiology and prediction of gestational diabetes mellitus. Int J Mol Sci. 2015;16(6):13442-73.

8. Association AD. 13. Management of diabetes in pregnancy: Standards of Medical Care in Diabetes-2018. Diabetes Care. 2018;41(Supplement 1): S137-S43.

9. Simeonova-Krstevska S, Bogoev M, Bogoeva K, Zisovska E, Samardziski I, Velkoska-Nakova $V$, et al. Maternal and neonatal outcomes in pregnant women with gestational diabetes mellitus treated with diet, metformin or insulin. Open Access Macedonian J Med Sci. 2018;6(5):803.

10. Farrar D, Simmonds M, Bryant M, Sheldon TA, Tuffnell D, Golder S, et al. Treatments for gestational diabetes: a systematic review and meta-analysis. BMJ Open. 2017:7(6):2016-015557.

11. Barnes RA, Wong T, Ross GP, Jalaludin BB, Wong WW, Smart CE, et al. A novel validated model for the prediction of insulin therapy initiation and adverse perinatal outcomes in women with gestational diabetes mellitus. Diabetologia. 2016:59(11):2331-8.

12. Sapienza AD, Francisco RPV, Trindade TC, Zugaib M. Factors predicting the need for insulin therapy in patients with gestational diabetes mellitus. Diabetes Res Clin Pract. 2010;88(1):81-6.

13. Kouhkan A, Khamseh ME, Moini A, Pirjani R, Valojerdi AE, Arabipoor A, et al. Predictive factors of gestational diabetes in pregnancies following assisted reproductive technology: a nested case-control study. Arch Gynecol Obstet. 2018:298(1):199-06.

14. Jalaludin B. Gestational diabetes mellitus: who requires insulin therapy? Aust N Z J Obstet Gynaecol. 2011;51(5):432-6.

15. Mitra S, Nayak PK, Sahoo J, Mathew A, Padma A, Kamalanathan S, et al. Predictors for antenatal insulin requirement in gestational diabetes. Gynecol Endocrinol. 2014;30(8):565-8

16. Jafari-Shobeiri M, Ghojazadeh M, Azami-Aghdash S, Naghavi-Behzad M, Piri R, Pourali-Akbar $Y$, et al. Prevalence and risk factors of gestational diabetes in Iran: a systematic review and meta-analysis. Iran J Public Health. 2015; 44(8):1036.

17. Poolsup N, Suksomboon N, Amin M. Effect of treatment of gestational diabetes mellitus: a systematic review and meta-analysis. PLoS One. 2014; 9(3):e92485.

18. Chen M, Wu L, Zhao J, Wu F, Davies MJ, Wittert GA, et al. Altered glucose metabolism in mouse and humans conceived by in-vitro fertilization (IVF). Diabetes. 2014;63(10):3189-98.

19. Watanabe M, Katayama A, Kagawa H, Ogawa D, Wada J. Risk factors for the requirement of antenatal insulin treatment in gestational diabetes mellitus. J Diabetes Res. 2016;2016:9648798.

20. Pertot T, Molyneaux L, Tan K, Ross GP, Yue DK, Wong J. Can common clinical parameters be used to identify patients who will need insulin treatment in gestational diabetes mellitus? Diabetes Care. 2011:34(10):2214-6.

21. Bakiner O, Bozkirli E, Ozsahin K, Sariturk C, Ertorer E. Risk factors that can predict antenatal insulin need in gestational diabetes. J Clin Med Res. 2013; 5(5):381.

22. Meshel S, Schejter E, Harel T, Maslovitz S, Germez N, Elimelech B, et al. Can we predict the need for pharmacological treatment according to demographic and clinical characteristics in gestational diabetes? J Matern Fetal Neonatal Med. 2016;29(13):2062-6. 
23. González-Quintero VH, Istwan NB, Rhea DJ, Tudela CM, Flick AA, De la Torre $\mathrm{L}$, et al. Antenatal factors predicting subsequent need for insulin treatment in women with gestational diabetes. J Women's Health. 2008;17(7):1183-7.

24. Cerny D, Sartori C, Rimoldi SF, Meister T, Soria R, Bouillet E, et al. Assisted reproductive technologies predispose to insulin resistance and obesity in male mice challenged with a high-fat diet. Endocrinology. 2017;158(5):1152-9.

25. Szymanska M, Horosz E, Szymusik I, Bomba-Opon D, Wielgos M. Gestational diabetes in IVF and spontaneous pregnancies. Neuro Endocrinol Lett. 2011; 32(6):885-8.

26. Nunes VA, Portioli-Sanches EP, Rosin MP, da Silva Araújo M, Praxedes-Garcia $P$, Valle MM, et al. Progesterone induces apoptosis of insulin-secreting cells: insights into the molecular mechanism. Journal of Endocrinology. 2014; 221(2):273-84.

27. Wada T, Hori S, Sugiyama M, Fujisawa E, Nakano T, Tsuneki H, et al. Progesterone inhibits glucose uptake by affecting diverse steps of insulin signaling in 3T3-L1 adipocytes. Am J Physiol-Endocrinol Metab. 2010;298(4):E881-E8.

28. Yildizfer F, Donma O, Yen M, Ekmekci O, Kul ZAK, Keser Z, et al. In vitro fertilization, levels of pro-inflammatory factors and lipid peroxidation. Int J Fertility Sterility. 2015;9(3):277.

29. Kumari $\mathrm{R}$, Singh $\mathrm{H}$. The prevalence of elevated high-sensitivity $\mathrm{C}$-reactive protein in normal pregnancy and gestational diabetes mellitus. J Fam Med Primary Care. 2017:6(2):259.

30. Brahimaj A, Ligthart S, Ghanbari M, Ikram MA, Hofman A, Franco OH, et al. Novel inflammatory markers for incident pre-diabetes and type 2 diabetes: the Rotterdam study. Eur J Epidemiol. 2017;32(3):217-26.

\section{Publisher's Note}

Springer Nature remains neutral with regard to jurisdictional claims in published maps and institutional affiliations.

Ready to submit your research? Choose BMC and benefit from:

- fast, convenient online submission

- thorough peer review by experienced researchers in your field

- rapid publication on acceptance

- support for research data, including large and complex data types

- gold Open Access which fosters wider collaboration and increased citations

- maximum visibility for your research: over $100 \mathrm{M}$ website views per year

At BMC, research is always in progress.

Learn more biomedcentral.com/submissions 